\title{
CULTURA ESCOLAR E SUA RELAÇÃO COM O SABER MATEMÁTICO: OS SENTIDOS DA DOCÊNCIA REVELADOS NOS CADERNOS DE ANOTAÇÕES DE UMA PROFESSORA PRIMÁRIA
}

\author{
LA CULTURA ESCOLAR Y SU RELACIÓN CON EL CONOCIMIENTO \\ MATEMÁTICO: LOS SIGNIFICADOS DE LA ENSEÑANZA DESVELADOS EN LOS \\ CUADERNOS DE UN MAESTRO DE PRIMARIA
}

\section{SCHOOL CULTURE AND ITS RELATIONSHIP TO MATHEMATICAL KNOWLEDGE: THE SENSES OF TEACHING REVEALED IN THE NOTEBOOKS OF A PRIMARY TEACHER}

RESUMO: Nesse artigo são analisados aspectos da memória educativa, cultural e social do sertão nordestino brasileiro, tendo como fonte de pesquisa os cadernos de anotações de professores primários para compreender o ensino de matemática desenvolvido nos anos iniciais do ensino fundamental no período compreendido entre 1950 e 1990. Os cadernos escolares permitem produzir conhecimentos por conter histórias, contextos socioeconômicos, políticos, culturais e educacionais gestados em temporalidades diversas. O objetivo deste estudo é identificar os conteúdos abordados na escola e aspectos relacionados aos saberes elementares de matemática. Como referências teóricas foram adotadas a concepção de cultura escolar defendida por Viñao Frago (2008) e o conceito de relação com o saber de Bernard Charlot (2000; 1996) que traz a noção de relação entendida como conjunto de significados e espaço de atividades do sujeito, inscritos num tempo. Adotando como referencial teórico-metodológico a História Cultural a partir das proposições de Roger Chartier (1990) e considerando as pesquisas no âmbito da história das disciplinas escolares, empreendidas por André Chervel (1990), o texto ainda considera o paradigma indiciário, de Carlo Ginzburg (1989), na busca da representação do passado e do presente da educação matemática na formação de professores.

PALAVRAS-CHAVE: História da educação matemática. Cadernos escolares. Cultura escolar.

RESUMEN: En este artículo se analizan aspectos de la memoria educativa, cultural y social del hinterland nororiental brasileño, teniendo como fuente primaria de investigación los cuadernos de apuntes de maestros de primaria para comprender la enseñanza de las matemáticas desarrollada en los primeros años de la escuela primaria en el período. entre 1950 y 1990. Los cuadernos escolares permiten producir conocimiento porque contienen historias, contextos socioeconómicos, políticos, culturales y educativos generados en diferentes momentos. El objetivo de este estudio es identificar los contenidos cubiertos en la escuela y los aspectos relacionados con los conocimientos elementales de la matemática. Como referentes teóricos se adoptaron el concepto de cultura escolar defendido por Viñao Frago (2008) y el

\footnotetext{
${ }^{1}$ Universidade de Pernambuco (UPE), Petrolina - PE - Brasil. Professora Permanente dos Programas de PósGraduação em Formação de Professores e Práticas Interdisciplinares (PPGFPPI) e Educação Matemática e Tecnológica (EDUMATEC). Doutorado em Educação (USP). ORCID: https://orcid.org/0000-0002-4812-8412. E-mail: iracema.cusati@upe.br
}

RPGE- Revista on line de Política e Gestão Educacional, Araraquara, v. 25, n. 2, p. 1119-1134, maio/ago. 2021. e-ISSN: 1519-9029 
concepto de relación con el conocimiento de Bernard Charlot (2000; 1996) que trae la noción de relación entendida como un conjunto de significados y espacio de actividades del sujeto, inscrito en un tiempo. Adoptando la Historia Cultural como marco teórico-metodológico a partir de las proposiciones de Roger Chartier (1990) y considerando la investigación en el contexto de la historia de las asignaturas escolares, realizada por André Chervel (1990), el texto sigue considerando el paradigma de acusación de Carlo Ginzburg (1989), en la búsqueda de la representación del pasado y presente de la educación matemática en la formación del profesorado.

PALABRAS CLAVE: Historia de la educación matemática. Cuadernos escolares. Cultura escolar.

ABSTRACT: In this article, aspects of the educational, cultural and social memory of the Brazilian Northeastern hinterland are analyzed, using the notebooks of primary teachers as a research source to understand the teaching of mathematics developed in the early years of elementary school in the period between 1950 and 1990. School notebooks make it possible to produce knowledge because it contains stories, socioeconomic, political, cultural and educational contexts created in different time periods. The aim of this study is to identify the content covered in the school and aspects related to elementary knowledge of mathematics. School notebooks allow us to produce knowledge because they contain historical, socioeconomic, political, cultural and educational contexts which were gestated in different time periods. The goal is to identify the contents covered and aspects related to elementary knowledge of mathematics. As theoretical references were adopted the understanding of Viñao Frago (2008) about school culture and the concept of Bernard Charlot (2000; 1996) about relationship with knowledge that brings the notion of relationship understood as a set of meanings and space for the subject's activities, inscribed at a certain time. Adopting Cultural History as a theoretical-methodological framework based on the propositions of Roger Chartier (1990) and considering research in the context of the history of school subjects, undertaken by André Chervel (1990), the text still considers Carlo Ginzburg's evidential paradigm (1989), in the search for representing the past and the present of mathematical education in teacher education.

KEYWORDS: History of mathematical education. School notebooks. School culture.

\section{Introdução}

Os cadernos escolares, guardiões de memórias, permitem desenvolver pesquisa e produzir conhecimentos pois neles estão registradas variadas formas de saber e fazer, histórias, contextos socioeconômicos, políticos, culturais e educacionais gestados em temporalidades diversas. Os cadernos em questão também permitem construir interpretações acerca da educação matemática disseminada em diferentes momentos históricos e apreender um conjunto de situações, fatos e experiências singulares do cotidiano escolar vivenciado pelos professores atuantes no período investigado, entre 1950 e 1990. 
O presente estudo suscita discussões teórico-metodológicas na área da história da educação e, mais especificamente, da história da educação matemática que, fundantes nas publicações de Valente $(2014 ; 2008$; 2006), colocam em evidência a multiplicidade de temas e possibilidades de pesquisa e de produção de conhecimento, ao considerar os contextos sóciohistóricos nos quais os referidos cadernos se inserem.

O pressuposto de que os arquivos escolares são mediadores de múltiplos sentidos na História propicia caminhos de investigação e de formação dos estudantes para lidarem com a memória e a história da educação. Os cadernos escolares permitem conhecer a escola por dentro em suas especificidades, seus saberes, sua forma de organização e suas práticas curriculares.

A cultura escolar entendida como o conjunto de teorias, normas, ideias, princípios, regras, rituais, rotinas, hábitos, práticas, formas de fazer e de pensar propicia aproximação das tradições, regularidades e regras que são partilhadas nas instituições de ensino pelos envolvidos no processo educativo. Por meio dos arquivos escolares é possível conhecer o interior da escola, suas especificidades, seus saberes, sua organização e suas práticas curriculares. Em contato com os estudantes que participam de projetos de iniciação científica há a possibilidade de questionar e criar novos saberes a partir do diálogo com as fontes, rompendo com uma visão linear da história, relativizando suas verdades e problematizando conceitos muitas vezes consolidados e veiculados em materiais didáticos.

O principal objetivo dessa pesquisa foi utilizar os cadernos escolares como fontes para a compreensão de como ocorreu o ensino de matemática em escolas primárias no sertão e, mais especificamente, analisar sinais do que era ensinado à época, identificando os conteúdos abordados e os aspectos relacionados aos saberes elementares da matemática. Como referência teórica, é utilizada a compreensão de Viñao Frago (2008) sobre cultura escolar, de Bernard Charlot (2000) sobre o saber e de Carlo Ginzburg (1989) sobre o paradigma indiciário na busca de uma representação do passado e do presente do cotidiano escolar. Ao analisar os cadernos buscou-se também compreender as concepções de ensino e as estratégias adotadas em relação à matemática escolar e às orientações veiculadas por obras e autores influenciados pelo ideário do Movimento da Matemática Moderna.

Mogarro (2005, p. 104), contribui com nossa reflexão ao retratar que por meio dos arquivos e das informações cunhadas nos documentos escolares é possível compreender "os vários discursos produzidos pelos atores educativos - professores, alunos, funcionários e autoridades locais e nacionais, pois têm representações diversas sobre a escola". A autora nos revela que os arquivos registram a informação sobre a escola como um conjunto homogêneo 
que "ocupa um lugar central e de referência no universo das fontes de informação que podem ser utilizadas" (p. 104).

Segundo Mogarro (2005) a cultura escolar é constituída por um conjunto de teorias, saberes, ideias e princípios, normas, regras, rituais, rotinas, hábitos e práticas; que nos remetem às formas de fazer e de pensar, aos comportamentos sedimentados ao longo do tempo e que se apresentam como tradições, regularidades e regras, muitas vezes mais subentendidas do que expressas no compartilhamento feito pelos atores educativos no seio das instituições. Essa cultura constitui um substrato formado, ao longo do tempo, por camadas entrelaçadas que demandam análise num processo historiográfico de investigação sobre a cultura escolar e as influências recebidas.

Portanto, olhar para o sertão como um universo cultural no semiárido nordestino, num intenso diálogo com as fontes, com a historiografia renovada e com os estudos culturais, oportunizou interrogar os elementos constituintes e as percepções dos atores sociais conectados numa base territorial com vínculos de afinidades, práticas sociais e econômicas, interações internas e articulações exteriores preservadas num cenário da totalidade histórica.

Desse modo, a história e a educação estarão sempre em construção em função de sua relevância para a formação de cidadãos, dos questionamentos que contribuirão para desenvolver uma consciência crítica que, inevitavelmente, conduzirá modos de ser e de agir que impulsionam a transformação social e a perspectiva de uma nova história da educação matemática.

\section{Revisão bibliográfica}

Antes de tratar dos dados encontrados na pesquisa em cadernos escolares, vale destacar alguns pesquisadores que há muito discutem sobre pesquisas com cadernos escolares. Eles apresentam o conceito de caderno de formas distintas e conforme Viñao Frago (2008) utiliza, o conceito estrito de caderno é adotado como um suporte comum aos alunos da escola. Contudo, sua utilização tornou-se generalizada apenas no século XIX.

Chartier $(2007$, p. 23) acrescenta que "essa fonte é, ao mesmo tempo, fascinante e enigmática, difícil de tratar e de interpretar, justamente por sua aparente banalidade". De fato, apesar de compor o cotidiano escolar os cadernos escolares são, em sua grande maioria, descartados ao final do ano letivo ou, antes, quando as folhas que são atribuídas a escrita se esgotam. Também, as pessoas os utilizam como se fossem ahistóricos e, talvez por isso, os pesquisadores tenham demorado para percebê-los como fonte de investigação. 

identificou as dificuldades de elaboração de conceitos e modelos teóricos que parametrizassem problemáticas próprias de pesquisa do campo assegurando que

\begin{abstract}
A maioridade da história da educação matemática, ao que tudo indica, terá como caminho a trilhar aquele de transformar-se da condição de especialidade, seja da História da Matemática, da Educação Matemática, ou mesmo da História/História da Educação, para a plenitude de um campo científico, erigindo-se como uma disciplina. E para isso será necessário a ultrapassagem de objetos de pesquisa - que hoje, em boa medida, vêm sendo tomados do real empírico, de sua aparência fenomenológica (níveis de escolaridade do ensino de matemática, conteúdos de ensino matemático, formação de professores de matemática, metodologias etc. são exemplos disso) (...) para a construção teórica de objetos de conhecimento (VALENTE, 2014, p. 330).
\end{abstract}

Por meio desse estudo, evidencia-se que os cadernos escolares proporcionam uma gama de possibilidades de pesquisa no campo da História da Educação, da Alfabetização e da Educação Matemática em relação a uma diversidade de abordagens e pontos de vista. Todavia, dependendo do tema a ser tratado, os cadernos escolares apresentam limites, ao serem utilizados como única fonte de pesquisa, pois eles não permitem observar o que acontece no cotidiano das salas de aula.

No caderno escolar, em geral, é destacado o registro dos conteúdos selecionados pelo professor. Contudo, não consta no caderno, por exemplo, apontamentos de como foi desenvolvida determinada atividade ou o tempo que ela levou para ser concluída, nem quais foram os membros participantes e o que foi discutido durante o processo de sua construção. Nesse sentido, a afirmação de Viñao Frago (2008, p. 25) é plausível para uma reflexão sobre currículo:

[...] Nem tudo está nos cadernos. Eles silenciam, não dizem nada sobre as intervenções orais ou gestuais do professor e dos alunos, sobre seu peso e o modo como ocorrem e se manifestam, sobre o ambiente ou clima da sala de aula, sobre as atividades que não deixam pistas escritas ou de outro tipo, como os exercícios de leitura (a leitura em voz alta, por exemplo) e todo o mundo oral.

Com certeza, há de se descartar a possibilidade de reconstrução de um currículo real a partir dos estudos nos cadernos escolares. Porém, como em toda operação histórica, a intenção nesta investigação é aproximar do passado e reconstruí-lo de modo parcial e com um enfoque determinado pois, ainda apoiando em Viñao Frago (2008), os cadernos não são utilizados da mesma forma em lugares diferentes, pois é o olhar do pesquisador que permitirá emergir os dados. 
Outra reflexão necessária alimentada pelo pesquisador é que os cadernos "não são apenas um produto da atividade realizada [...] e da cultura escolar, mas também uma fonte que fornece informação - por meio, sobretudo, de redações e composições escritas - da realidade material da escola e do que nela se faz" (VIÑAO FRAGO, 2008, p. 16).

Nesse sentido, o uso dos cadernos escolares nas pesquisas acadêmicas vem ganhando espaço seja como fonte de pesquisa ou como objeto de estudo para o entendimento de temas relacionados à educação pois, da materialidade e dos registros, neles contidos e que podem ser problematizados; são constituídos o núcleo da investigação.

Os cadernos escolares possibilitam compreender as culturas escolares, a transmissão de valores e modos de pensar, a história do currículo, a cultura escrita, as reformas e as inovações educativas (VIÑAO FRAGO, 2008).

Neste artigo, com enfoque de análise nos valores que permearam as práticas escolares, a cultura material é considerada "parte integrante da cultura escolar e coloca os espaços educativos, os edifícios escolares, o mobiliário e os materiais de ensino na agenda de investigação, como objeto de estudo fundamental para a compreensão dos processos educativos e das práticas de ensino" (MOGARRO, 2010, p. 92).

Desse modo, os cadernos escolares são considerados portadores de sentidos ligados ao "sistema de valores e representações sociais que ultrapassam a função de objeto destinado, somente, ao registro do processo de aprendizagem" (CORDOVA, 2016, p. 209). Nesse tocante, podem ser analisados por diferentes perspectivas e podem ser portadores de vários sentidos: “como escritas ordinárias, testemunhos de uma construção de si; relíquias conectadas com uma sensibilidade nostálgica[...]" (CUNHA; SOUZA, 2015, p. 13). Podem, ainda, depor "sobre uma pluralidade de significações: orientação do ato educativo, em que se captam objetivos políticos e sociais, além de teorias pedagógicas, [...] estética da ilustração dos modelos de escrita e, finalmente, as interfaces econômicas [...]” (FERNANDES, 2008, p. 50-51).

Ao concordar com a afirmação de Meneses (1998, p. 95) "toda operação com documentos, portanto, é de natureza retórica", a intenção é ampliar a reflexão no que se refere à retórica do dito e do não dito pois, ainda segundo a autora, os cadernos trazem marcas de registro que sinalizam posições em um quadro social, mas omitem situações tais como: os acordos feitos por meio da oralidade, as formas de apropriação dos alunos e professores e o tempo dedicado às atividades documentadas.

Por último, vale destacar que os cadernos escolares não são neutros, mas sim, resultados da cultura escolar de um determinado lugar, de um determinado tempo histórico, pois são fontes tão complexas quanto outras e que, por isso, se tornam objetos de pesquisa interessantes por 
serem suportes utilizados pelas crianças, a partir de um processo diário que permite registro de interações que se estabelecem durante as atividades desenvolvidas nas aulas. Neles constam imagens e representações sociais sobre a infância, a escola, a família, entre outros temas similares que explicitam aculturação escrita.

A perspectiva da história cultural, tal como a entende Chartier (1990), tendo como objeto a ciência e a história, "tem por principal objeto identificar o modo como em diferentes lugares e momentos uma determinada realidade cultural é construída, pensada, dada a ler". (CHARTIER, 1990, p. 17).

Intimamente imbricadas nesse processo, encontram-se as relações identitárias da formação e da profissionalidade docente, que implicam em determinadas formas de se engajar nos processos de ensino e de aprendizagem. Charlot (2000, p. 72) essencialmente nos adverte que "[...] qualquer relação com o saber comporta também uma dimensão de identidade: aprender faz sentido por referência à história do sujeito, às suas expectativas, à sua concepção de vida, às suas relações com os outros [...]”.

Charlot $(2000 ; 1996)$ auxilia a aprofundar a reflexão sobre a relação com o saber ao abordar que, embora sendo de um sujeito, essa relação é também social. A relação com o saber e com o aprender de um grupo de sujeitos explica o contexto da maneira de lidar com a vida, que é marcada pela busca de construir possibilidades de agir, de ações possíveis no espaço do cotidiano.

Outro importante ponto que Charlot (2000,p. 68) alerta é para o fato de que "o saber só pode assumir a forma de objeto através da linguagem; melhor ainda, da linguagem escrita [...]".

Diante da panorâmica dos teóricos citados nesta seção, que consideram os cadernos escolares como fonte e objeto de pesquisa, e, entendendo que estes constituem relevante fonte documental para a análise das culturas e práticas escolares no estudo de instituições escolares, é apresentado a seguir o levantamento de dados que foi realizado na presente pesquisa.

\section{Metodologia}

O contexto que abarca este trabalho, um convite para aproximar dos materiais que há anos fazem parte da vida escolar, para retirá-los de sua rotina diária e colocá-los numa posição de destaque, é permeado pela pretensão de resgatar o sentido das práticas escolares a partir de sua cotidianidade.

Ao propor uma perspectiva diferenciada, considerando as marcas (indícios) da singularidade cultural presente nos cadernos escolares, sejam por anotações, desenhos ou 
figuras recortadas e neles coladas, fornecem indícios de usos e convidam a um processo de interpretação que transforma o objeto usual num bem de valor pessoal e singular que narra a história.

Também é levado em consideração que os materiais só adquirem uma existência porque estão diretamente ligados à produção de determinado conhecimento escolar e por isso são percebidos no campo de representações e imagens dos alunos.

Para esse estudo, de natureza qualitativa e ontológica, foram selecionados 8 (oito) dos 27 (vinte e sete) cadernos escolares do acervo da Professora Maria Franca Pires. A professora, popularmente conhecida como Franca Pires, nasceu em 5 de novembro de 1921, na cidade de Remanso no Sertão da Bahia, diplomou-se professora em 1939 na Escola Rural Nossa Senhora Maria Auxiliadora em Petrolina-PE. Em 1943 foi aprovada no concurso para o Magistério Primário da rede estadual de ensino da Bahia e nomeada em Salvador em 1947. Em 1950 regressou a sua terra natal e em 1951 solicitou transferência para Juazeiro onde atuou e permaneceu até seu falecimento em 1988.

Os cadernos da professora têm registradas anotações que retratam suas inúmeras experiências, como memórias da infância, a morte prematura da mãe, a trajetória no colégio de freiras Maria Auxiliadora, o curso de magistério em Salvador, pautas de reuniões, planos de aula, entrevistas com integrantes e lideranças de grupos culturais, planejamentos semestrais e anuais das disciplinas de Língua Portuguesa, Matemática e Ciências. Essas anotações desvelam indícios sobre como Franca Pires aproxima de diferentes contextos (político-social-cultural) da cidade de Juazeiro (BA) e de regiões circunvizinhas, que possibilitaram a produção de novos saberes e fazeres pautados em suas vivências.

Em relação aos cadernos escolares, fontes dessa investigação, foram selecionados aqueles que apresentavam registros e representações de conteúdos matemáticos por considerar que as análises dos cadernos revelam vestígios sobre o que os professores privilegiavam ao ensinar, o método, as atividades, as estratégias atreladas ao contexto social e econômico no qual foram produzidos.

A pergunta que se coloca é: quais vestígios da influência do Movimento da Matemática Moderna (MMM) na práxis da Professora Maria Franca Pires e quais registros traduzem traços da constituição da educação matemática enquanto campo de pesquisa? A partir das análises minuciosas nos 8 cadernos considerados para esse estudo, serão explicitados os indícios de representações matemáticas que apontam para uma aproximação ao ideário do MMM na busca de compreensão da influência desse movimento na formação e profissionalização da professora Franca Pires. 
A prática da historiografia pode ser comparada a atividades que necessitam da análise de indícios para tecer explicações. O italiano Carlo Ginzburg sistematizou esse tipo de saber e cunhou a expressão "paradigma indiciário" tanto para a história quanto para as outras áreas do conhecimento que partilham da prática de "rastreamento de sinais, indícios, signos" que remetem a algum evento, mas sem captá-lo em sua integridade.

A História da Educação Matemática nesse estudo caracteriza como elemento orientador na busca de referências para compreender os registros de situações práticas do cotidiano da professora e as particularidades que foram destacadas são apenas pequenos indícios das muitas análises desta natureza.

\section{Resultados e discussão}

A preocupação com métodos de ensino que possibilitassem dirimir as dificuldades no ensino e na aprendizagem em escolas primárias, embora tema recorrente na literatura, encontra no acervo em estudo indícios de recepção, circulação e apropriação de concepções pedagógicas de seu tempo.

Para Valente (2006), há a necessidade de que sejam construídos referenciais da Educação Matemática levados a cabo em grande parte da segunda metade do século XX no Brasil e, para tanto, é imprescindível intensificar as pesquisas, objetivando atingir a maior proximidade possível do que efetivamente representou o Movimento da Matemática Moderna (MMM) na sua época e as influências que, porventura, ainda exerçam nas ações pedagógicas dos professores de Matemática.

O MMM ocorreu num momento histórico em que o mundo passava por grandes mudanças culturais, políticas, sociais e econômicas. No Brasil, esse momento histórico caracterizava-se por um período de transição da base econômica e política em que, sob um regime de ditadura, todos os discursos eram voltados para a ideia de modernização e de desenvolvimentismo, apesar do país apresentar problemas sociais graves. Os acontecimentos que ocorriam no campo da economia e da política mantinham estreitas ligações com o campo científico-tecnológico e fundamentavam as ideias de mudanças apresentadas pelo Movimento da Matemática Moderna que legitimava o conceito de "moderna" por considerar que a "nova matemática" superaria os limites estabelecidos pela antiga matemática. Logo, a construção desses referenciais se torna fundamental para que seja mais elaborada a ideia da abrangência dos fatos produzidos por esse movimento e as implicações desses fatos nas práticas escolares. 
Para Silva e Valente (2008), os cadernos escolares podem traduzir muito sobre o processo de ensino e de aprendizagem que ocorreu em outras épocas.

$\mathrm{Na}$ busca por vestígios para a escrita dessa trajetória histórica, os cadernos de anotações da professora Franca Pires, constitutivos da cultura escolar, ampliam a possibilidade de compreender tanto a história da educação matemática na região do submédio São Francisco quanto o que se passava no interior das instituições escolares. Também se busca a compreensão acerca das apropriações das propostas para o magistério primário no momento de vigência do Movimento da Matemática Moderna.

Tentando entender o currículo e as práticas dos professores, atuantes na segunda metade do século XX, em relação às aproximações, distanciamentos e entrecruzamentos com a cultura escolar vigente, foram identificados vestígios de regras e práticas da matemática que se formalizou na escola primária nos cadernos do acervo investigado.

A década de 1960 foi marcada por grandes mudanças no ensino de matemática em todo o Brasil, devido ao Movimento da Matemática Moderna (MMM). Surgido na Europa e nos Estados Unidos, o ideário do MMM chegou ao Brasil no início da década de 1960 caracterizado por ter sido um movimento de reformulação do currículo da matemática para o ensino básico cuja principal particularidade, manifestada pelos representantes do movimento, era a discussão nos grupos da nova proposta de democratização do ensino da matemática tornando-a mais prática e mais contextualizada bem como estabelecendo formas de implementação nas escolas. Vários grupos de professores se formaram nesse período em diversas regiões do Brasil com o objetivo de conhecer, estudar e compreender para colocar em prática a matemática moderna.

Nesses novos ares que pairavam sobre a cidade de Juazeiro, Franca Pires criou e presidiu a Associação de Pais e Mestres que viria a desenvolver ações por 20 anos, período em que a professora teve a oportunidade real de pôr em prática seu aprendizado e tornar viável essa identificação, como é possível verificar nas fontes de pesquisa utilizadas nessa investigação e nos vestígios no tempo presente relativos à história da matemática escolar.

Fruto de um aprendizado da época da Escola Normal, a professora primava pela ideia de que o relacionamento escola-família era indispensável ao bom andamento dos trabalhos escolares e à formação de cidadãos era premente na escola. Também vislumbrava uma Educação Matemática cidadã, “na qual o conhecimento apreendido, certamente, deverá contribuir para que os estudantes possam adquirir competências e habilidades capazes de imputar-lhes ações que convirjam para a melhoria da qualidade de vida de cada um, individual e coletivamente" (MENDES, 2009, p. 16). 
O ideal da matemática, seu ensino e saber, estão registrados nos cadernos de números 3, 4. 7, 8, 9, 10, 20 e 22 que compõem o acervo da professora Franca Pires. Nestes cadernos se entrelaçam os conteúdos curriculares e as propostas de ensino documentadas pela professora em planejamentos semestrais e anuais e também nos planos de aulas, quais sejam: teoria dos conjuntos, conjunto dos naturais e dos racionais e suas operações, sistema métrico decimal, perímetro, área, volume, sólidos geométricos, planificações, classificação de figuras planas, noções de estatística, resolução de problemas e avaliação em matemática.

Notadamente, era uma professora preocupada em habilitar os alunos no rigor do raciocínio lógico e na linguagem clara e precisa, além de ressaltar a ênfase em terminologia e conceituação que eram prerrogativas da teoria dos conjuntos e das medidas em geometria. Esses aspectos eram enfatizados em anotações de fim de página, de orelha e em pequenos registros em destaque ao longo das anotações nos variados cadernos. O estudo desses cadernos poderá revelar importantes elementos constituintes de uma trajetória histórica da disciplina escolar (CHERVEL, 1990), nesse caso da matemática ensinada na escola.

Iniciando pelo caderno de número 3, vale destacar que é um caderno pequeno medindo $21,1 \mathrm{~cm}$ x 14,8 cm, aramado, contendo 364 páginas, capa colorida com a imagem de um sapato com cachorrinhos dentro e flores ao lado; há, ainda na capa, uma figura colada retratando um ambiente urbano. Na parte central está manuscrito número 3. As contracapas contêm anotações diversas de endereços, frases e contas matemáticas. Diversas entrevistas gravadas com representantes de variados setores da comunidade estão transcritas neste caderno abordando os seguintes temas: carnaval de 1914 (lista com nomes de pessoas que saíram nos carros de "Embaixadores de Veneza"); sobre concurso de Rainha do Carnaval e relação com o Bazar Royal; participação de entrevistado no grupo Novos Baianos; história de assombração; barragem São Geraldo; divisão de Águas do Rio São Francisco; enchentes; localização do ponto mais alto de Juazeiro; informações sobre extinção do corpo musical da Apolo, cinema Ideal; serviço de água encanada, origem de Juazeiro, desenvolvimento econômico, imprensa, religiões, política, educação, cultura e instalações da Santa Casa.

O caderno de número 4 é pequeno, mede $20,5 \mathrm{~cm}$ x 14,7 cm, aramado, contém 138 folhas, capa colorida nas cores branco, rosa e amarelo, destinado a anotações de promoção de Cursos e de organização da produção e da venda de artesanato. No centro da capa está colado um pedaço de papel onde encontra-se manuscrito "1980" e por cima o número 4; no local da capa destinado à identificação do caderno está manuscrito "Maria Franca Pires - 1980". Os registros nesse caderno contêm anotações da reunião com professoras, datada de 14/01/1980, sobre respostas ao questionário da FUNDESCOLA e assuntos da pré-escola. Há anotações de 
planejamento de cursos de artesanato nos projetos de Juazeiro nas localidades Maniçoba, Mandacaru, Curaçá, Tourão; lista com nomes de instrutoras por curso, datada de 28/01/1980; anotações de produção dos cursos por semana nos municípios e contas matemáticas. Há também listas de produção dos cursos de crochê, bordado à mão, corte e costura, bonecas e animais de pano, tapeçaria. Finaliza com anotações sobre Feira e Posto de artesanato.

O caderno de número 7, pequeno, com dimensões $22 \mathrm{~cm}$ x $16 \mathrm{~cm}$, contém 47 folhas, capa de papel flexível na cor laranja. A capa traz a palavra COMPANHEIRO, impressa na cor azul e a imagem de um menino sorridente agachado brincando com um carrinho de polícia na terra. Além disso, ainda na capa, está manuscrito "Catecismo" e "Maria Pires". O fundo do caderno traz um desenho e um texto educativos sobre a energia elétrica.

O caderno de número 8, tem registrados planejamentos de aulas, eventos e reuniões. Sua descrição é de um caderno pequeno com medidas $21,7 \mathrm{~cm}$ x 15,5 cm, aramado, que contém 77 folhas, capa quadriculada e colorida em azul, cinza e branco. No centro da capa está manuscrito, como um título, "Lendas e outros"; ainda na capa, no espaço destinado à identificação, está manuscrito "Planejamentos diversos - Maria Franca Pires - 1971". Nas contracapas, encontram-se manuscritos citações de pensamentos, lembretes e anotação de um endereço. Os planejamentos de ensino são de religião, gincana de aniversário de Juazeiro, matemática, informações sobre catataus, entrevistas sobre candomblé, toré, bailes, ternos, reis de boi, congos.

O caderno de número 9 é pequeno, mede $22 \mathrm{~cm} \mathrm{x} 16 \mathrm{~cm}$, aramado, contém 92 folhas, capa colorida em branco, azul e rosa. Na capa, no local destinado à identificação do caderno está manuscrito “Maria Franca Pires - 'Pesquisas' - Cons. Luiz Viana, 101 - Juazeiro-Bahia”. $\mathrm{Na}$ contracapa encontram-se anotadas sete frases e uma relação de retratos e nomes de três pessoas (Lilina, Chico Cabana e Blandina).

O caderno de número 10 é pequeno com dimensões $21 \mathrm{~cm}$ x 14,5 cm, brochura, contém 75 folhas, capa colorida na cor verde, contendo uma imagem ao centro com duas crianças loiras brincando na areia de uma praia. No topo da capa está gravada a palavra "companheiro" na cor vermelha e no local destinado à identificação do caderno está manuscrito "Clube de mães: Piranga e Maria Goretti” e logo abaixo, em letras menores, “Ao uso de: Ma F. Pires”. Neste, constam anotações de organização de Clube de Mães: listas de nomes, reuniões, prestação de contas, cursos oferecidos, estatuto do Clube de Mães etc. Também há anotações de cursos para o ano de 1979 (porém, não há nenhum curso relacionado).

O caderno de número 20 é pequeno, com medidas de $22 \mathrm{~cm}$ x $15 \mathrm{~cm}$, aramado, contém 69 folhas, capa lisa na cor bege. No local da capa destinado à identificação do caderno está 
manuscrito "Planejamento - Maria Franca Pires - 1972". Os planejamentos registrados são de excursão, aulas e reuniões; informações sobre Folclore, no Brasil e em Juazeiro; de Semana da Proclamação da República e da Bandeira; a Semana da Criança; questionário sobre alguém (parece ser feito por crianças a Maria Franca Pires); rascunho de carta ao Capitão Esmeraldo, chefe da Companhia de Navegação do São Francisco, datada de 17 de julho de 1972; datas de nascimento de José Ronaldo Dewilson Oliveira, José Robério Dewilson Oliveira, Maria Tereza Dewilson Oliveira, Maria Olívia Dewilson Oliveira; além de histórias e poemas. Há o Planejamento de aula do dia 31/08/72: provas, ensaio, exercício de Matemática e assunto de propriedades da adição. Há anotações datadas do dia 12/09/72: planejamento de aula sobre poesias, lembretes, letras do Hino da Proclamação da República e do Hino à Bandeira.

O último caderno a analisar, o de número 22 , também um caderno pequeno com dimensões $23 \mathrm{~cm}$ x $16 \mathrm{~cm}$, aramado, contém 85 folhas, apresenta capa quadriculada e colorida em marrom e branco. No local da capa destinado à identificação do caderno está manuscrito "Maria Franca Pires - Apontamentos de Cursos - 1971". Nestas anotações constam etapas de desenvolvimento dos cursos composta pelos registros: Criatividade, Dinâmica de Grupo, Reforma de Ensino, Memorização, Relações Humanas, O Poder da Mente, Folclore; frases, pensamentos e citações; questionário sobre Rui Barbosa; planejamento para competição "Meu Bairro é o maior"; poemas, histórias e letras de músicas.

Portanto, vale ressaltar que nesses arquivos, além de documentos pessoais, também foram encontrados documentos de caráter pedagógico e institucional de fundamental importância para a historiografia do espaço escolar. Tais documentos, planejamentos e planos de aulas, atas de reuniões, fotos, cadernos de classe de ex-alunos e os cadernos de anotações da professora Franca Pires, revelam uma realidade pouco apreendida nos documentos oficiais.

De acordo com Vidal e Faria Filho (2005, p. 24), é preciso reconhecer que não há prática escolar desvinculada das condições materiais de sua efetivação. Nesse sentido, o acervo preservado de Franca Pires porta indícios das múltiplas maneiras como a professora constituiu a sua profissionalidade e suscita a investigação sobre as diferentes formas de apropriação de conhecimentos e saberes, "oferecendo ao pesquisador índices sobre as relações pretéritas dos sujeitos com a materialidade escolar ou sobre a formalidade das práticas escolares, e fazendoo recordar que as situações pedagógicas se constroem muito frequentemente por formas orais de socialização."

Essas considerações permitem concluir que os cadernos de Maria Franca Pires vinculam políticas educacionais regionais e nacionais, discurso escolar e científico sobre a aprendizagem 
da Matemática e como os saberes se articulam na trama dos cadernos, revelando uma cultura escolar.

\section{Considerações finais}

As atividades escolares trazem indícios dos saberes, dos valores morais e das condutas estimuladas no cotidiano escolar e que, portanto, fizeram parte das culturas escolares das instituições escolares nas quais foram desenvolvidas. As práticas escolares, vale ressaltar, são permeadas pelos programas, pelos decretos, pelas ideias pedagógicas em circulação e também pelas organizações do corpo docente, pelas oportunidades de formação destes, pelos espaços físicos e materiais. Por fim, é no ambiente escolar que são oportunizados espaços de usos criativos e inventivos, permeados pelas culturas escolares.

Nesse trabalho foi percebida a complexidade que investigações desse tipo acarretam. A análise empreendida não é e nem intenciona ser conclusiva nem definitiva, mas sugere a possibilidade de que em outros trabalhos de pesquisa possa ser ampliado, completado ou mesmo confrontado com o que foi feito até aqui. Enfim, esse trabalho tentou ilustrar uma investigação no campo da cultura material escolar evidenciando elementos das práticas escolares que configuram facetas predominantes de processos e fatos de cunho histórico-cultural dos afazeres do cotidiano escolar.

A partir dos cadernos analisados é possível verificar vestígios que apontam para o conhecimento e engajamento da professora Franca Pires com as discussões referentes ao ensino de matemática que refletem nas opções que foram feitas por ela em relação a sua vinculação e fixação no sertão. Seu trabalho avançou no sentido de aprofundar estudos e promover ações que contribuíram desde a seleção de pesquisadores com vasta produção na área para as formações em docência até as discussões com os pares em relação a educação matemática.

A educação, linha que teceu e conduziu a vida da professora em foco, costura e atravessa - plural, inclusiva, criativa, desbravadora e inovadora - os registros de Maria Franca Pires com a coerência que marcou sua existência e ethos profissional que constituiu a professora.

\section{REFERÊNCIAS}

CHARLOT, B. Da relação com o saber: elementos para uma teoria. Porto Alegre, RS: Editora Artmed, 2000.

CHARLOT, B. Relação com o saber e com a escola entre estudantes de periferia. Cadernos de Pesquisa, São Paulo, n. 97, p. 47-63, 1996. 
CHARTIER, A. Práticas de leitura e escrita: história e atualidade. Belo Horizonte, MG: Ceale/Autêntica, 2007.

CHARTIER, R. A história cultural: entre práticas e representações. Lisboa, Portugal:

Editora Difel; Rio de Janeiro, RS: Editora Bertrand Brasil S. A., 1990.

CHERVEL, A. História das disciplinas escolares: reflexões sobre um campo de pesquisa. Teoria \& Educação, 2, p. 177-229, 1990.

CORDOVA, T. Redações, cartas e composições livres: o caderno escolar como objeto da cultura material da escola (Lages/SC - 1935). História da Educação, Porto Alegre (RS), v. 20, n. 49, maio/ago. 2016. p. 209-226. Disponível em:

http://www.scielo.br/pdf/heduc/v20n49/2236-3459-heduc20-49-00209.pdf. Acesso em: 2 set. 2019.

CUNHA, M. T. S.; SOUZA, F. F. Viver e escrever: cadernos e escritas ordinárias de um professor catarinense (Sec XX). Florianópolis, SC: Insular, 2015.

FERNANDES, R. Um marco no território da criança: o caderno escolar. In: Mignot, A. C. V. (Org). Cadernos à vista: escola, memória e cultura escrita. Rio de Janeiro, RJ: EdUERJ, 2008. p. 49-68.

GINZBURG, C. Mitos, emblemas e sinais. Morfologia e história. São Paulo, SP: Companhia das Letras, 1989.

MENDES, I. A. Investigação histórica no ensino da matemática. Rio de Janeiro, RJ: Ed. Ciência Moderna, 2009.

MENESES, U. T. Bezerra de. Memória e cultura material: documentos pessoais no espaço público. Estudos Históricos. v. 21, p. 89-103, 1998. Disponível em:

http://bibliotecadigital.fgv.br/ojs/index.php/reh/article/view\%20File/2067/1206. Acesso em: 05 ago. 2019.

MOGARRO, M. J. Os arquivos escolares nas instituições educativas portuguesas. Preservar a informação, construir a memória. Pro-Posições, Campinas (SP), v. 16, n. 1, jan./abr. 2005.

MOGARRO, M. J. Cultura material e modernização pedagógica em Portugal (séculos XIX XX). Educatio Siglo XXI, v. 28, n. 2, p. 89-114, 2010. Disponível em:

http://repositorio.ul.pt/bitstream/10451/12308/1/Cultura_Material_e_moderniza\%C3\%A7\%C 3\%A3o_pedag\%C3\%B3gica.pdf. Acesso em: 5 set. 2019.

VALENTE, V. R. Livro didático e educação matemática: uma história inseparável. Zetetiké, São Paulo (SP), v. 16, n. 30, jul./dez. 2008.

VALENTE, W. R. (Org.). História da educação matemática. Problemáticas de pesquisa, fontes, referências teórico-metodológicas e históricas elaboradas. São Paulo, SP: LFEditorial, 2014. 
VALENTE, W. R. A matemática moderna nas escolas do Brasil: um tema para estudos históricos comparativos. Revista Diálogo Educacional, Curitiba (PR), v. 6, n. 18, p. 19-34, maio/ago. 2006.

VIDAL, D. G.; FARIA FILHO, L. M. Reescrevendo a história do ensino primário: o centenário da lei de 1827 e as reformas de Francisco Campos de Fernando de Azevedo. In: VIDAL, D. G.; FARIA FILHO, L. M. As lentes da história. Campinas, SP: Autores Associados, 2005. p. 7-39.

VIÑAO FRAGO, A. Os cadernos escolares como fonte histórica: aspectos metodológicos e historiográficos. In: MIGNOT, A. C. V. (Org.). Cadernos à vista: escola, memória e cultura escrita. Rio de Janeiro, RJ: EdUERJ, 2008. p. 15-28.

\section{Como referenciar este artigo}

CUSATI, I. C. Cultura escolar e sua relação com o saber matemático: os sentidos da docência revelados nos cadernos de anotações de uma professora primária. Revista on line de Política e Gestão Educacional, Araraquara, v. 25, n. 2, p. 1119-1134, maio/ago. 2021. e-ISSN:15199029. DOI: https://doi.org/10.22633/rpge.v25i2.15157

Submetido em: $27 / 05 / 2021$

Aprovado em: 15/06/2021

Publicado em: 01/08/2021 